\title{
Influence of bioregion and environmental factors on the growth, size and reproduction of Bonsmara cows
}

\author{
E.C. Webb ${ }^{1 \#}$, P.C. Visagie ${ }^{1}$, J. van der Westhuizen ${ }^{2}$ \& H.A. Snyman ${ }^{3}$ \\ ${ }^{1}$ Department of Animal and Wildlife Science, University of Pretoria, Private Bag X20, Hatfield, Pretoria, 0028, \\ South Africa \\ ${ }^{2}$ SA Studbook and Animal Improvement Association, P.O. Box 270, Bloemfontein, 9300, South Africa \\ ${ }^{3}$ Department of Animal, Wildlife and Grassland Sciences, University of the Free State, P.O. Box 339, Bloemfontein 9300 ,
} South Africa

(Received 21 January 2015; Accepted 26 June 2017; First published online 28 June 2017)

Copyright resides with the authors in terms of the Creative Commons Attribution 4.0 South African License.
See: http://creativecommons.org/licenses/by/4.0/za
Condition of use: The user may copy, distribute, transmit and adapt the work, but must recognize the authors and the South African
Journal of Animal Science.

\begin{abstract}
A better understanding of the influences of the bioregion (production environment) and environmental factors on the productivity of beef cows is vital in the pursuit of improving beef production. The influence of bioregion and important environmental factors in South Africa (temperature, rainfall, soil $\mathrm{pH}$, soil cation exchange capacity, soil organic carbon content, soil phosphorus (P) concentration, and grazing capacity) on production and reproduction traits of Bonsmara cows were analysed by means of cluster analysis and analysis of variance (ANOVA). Stepwise regression analyses were used to determine the influence of the different environmental factors (and possible non-additive genetic effects) on the production and reproduction efficiency of the cows. Results of the effects of bioregion and non-additive genetic effects (the contribution of which was not quantified per se) on beef cow productivity indicate that bioregion influenced production and reproduction traits of cows, while significant farm effects were also noted. Bonsmara farm influenced the production efficiency of cows through the implementation of management practices and breeding objectives. Environmental factors significantly influenced all production traits measured for Bonsmara cows. The extent of the effects of the combined influences of environmental factors on cow productivity depended on the physiological stage of animal growth and reproduction. Environmental effects on production efficiency were buffered by maternal effects at birth, but became more significant after weaning $(9 \%)$ to yearling age $(10 \%)$ and maturity. Most environmental factors studied influenced the production traits of cows, with rainfall and temperature having the largest influence. The negative influence of rainfall on cow productivity was attributed to its negative influence on grazing quality, through effects on soil $\mathrm{pH}$, phosphorus and soil organic carbon content. The small negative influence of temperature on the productivity of cows indicates that this breed is well adapted to the main South African beef production regions. It should be noted that in this study the non-additive genetic component was not separated from the environmental components.
\end{abstract}

Keywords: Beef cattle, bioregion, geographic location, growth curve, production efficiency

\# Corresponding author: Edward.webb@up.ac.za

\section{Introduction}

The external environment has a large influence on livestock production (Hafez, 1968; Bonsma, 1983). Environmental influences on livestock production can be direct, through effects on the animal's physiology, or indirect, through influences on the quantity and quality of animal feed sources. In extensive production systems cattle are mainly dependent on the natural grazing or forage for their nutritional needs (De Waal, 1990). The climate of a region affects the vegetation and thus grazing directly and indirectly. Direct influences occur through solar radiation, temperature, and moisture, which influence the distribution of plant species and their nutrient value. Indirect influences occur through the effects of climatological factors on soil conditions and fire regime (Schulze, 1997; Snyman, 2015). The major climatological factors that influence livestock production are rainfall and temperature (Hafez, 1968). The main constraints of livestock production in extensive production systems in South Africa are insufficient nutritional intake and specific nutrient deficiencies (De Waal, 1990). The nutritional value of extensive grazing is influenced by inter alia the soil nutrient status (McDonald et al., 2002). A large portion of the South African bioregions (production 
environment) is arid or semi-arid (Schulze, 1997), with high ambient temperatures which may adversely affect the adaptation of livestock during summer (Du Preez et al., 1992; De Jager, 1993).

The nutritional value of the diet of a grazing ruminant is determined by its nutritive value, digestibility, and intake (Meissner et al., 1999). The nutritional value and digestibility of the forage is determined by the chemical composition of the plants, which depends on the species, metabolic type of plant, stage of growth, season, sunlight, soil nutrient status and acidity, available soil water, and ambient temperature (McDonald et al., 2002; Snyman, 2009). Animal feed intake is linked to digestion (fermentation) rate. When intake is not limited by the digestibility of the feed, it is influenced by availability, palatability, water content, and forage management (Meissner et al., 1999). The production capacity of rangeland is influenced by a number of factors including plant composition (Snyman, 1999; Snyman, 2009), temperature (Tainton \& Hardy, 1999), the annual variation and distribution of rainfall (Snyman, 1998), and soil fertility (Scholes, 1990), which collectively influence rangeland condition (Snyman, 2009). All these factors invariably influence animal production (De Waal, 1990), but extensive cattle production in South Africa is influenced most by environmental conditions such as rainfall, temperature, and nutritional factors, as well as access to or a lack of minerals.

The influence of production region on cattle production has been investigated by a number of authors both in South Africa (Bonsma, 1983; Ronchietto, 1993; Webb \& Erasmus, 2013) and internationally (Leighton et al., 1982; Burfening et al., 1987). It is suggested that the natural variation in size of the same species of wild animals occurring in different environments is an indication that nature defines the "right" genetic material for efficiency in different ways in different environments (Johnson et al., 2010). The existence of optimal cow size for specific environments has been investigated by several authors (Bonsma, 1983; Buttram \& Willham, 1989; Arango \& Van Fleck, 2002; Taylor et al., 2008; Johnson et al., 2010; Echols, 2011). From the literature, it is evident that the bioregion has a significant influence on beef cow efficiency, although there is little consensus regarding the existence of an optimal mature cow size for specific bioregions (Taylor et al., 2008). These researchers concluded that production efficiency of beef cows is influenced by a combination of size, adaptive ability and bioregion.

The Bonsmara is the dominant South African beef cattle breed with more than 100000 registered animals (Scholtz, 2010). This breed was developed based on a 5/8 Afrikaner and 3/8 Exotic (Shorthorn/Hereford) breeding admixture and considerable emphasis was placed on selection for adaptive ability (Bonsma, 1983). Bonsmara breeding stock must be functionally efficient and all Bonsmara cattle must be screened for functional efficiency by breed inspectors, which is compulsory for registration of stud animals. The concept of 'functional efficiency' applied in Bonsmara cattle is based on the assumption that selection for phenotypic traits that have an influence on the animal's ability to adapt to the environment, will improve the animal's ability to express its reproduction and production potential (Bonsma, 1983). Bonsmara breeders commonly assume that specific types or sizes of cattle are better adapted to specific production regions in South Africa, based on the observations of Prof. J.C. Bonsma that adapted cows are of optimal size for the environment in which they occur, in order to adapt, produce and reproduce according to their full genetic potential. However, these concepts have not been proven conclusively and remain controversial. Bonsmara farmers believe that there is a tendency for Bonsmara cows in the eastern part of South Africa to be smaller and less reproductively efficient than those in the western parts of the country. This study, therefore, investigated the influence of production region, farm and certain environmental factors on the growth, size and reproduction of Bonsmara cows, as well as the existence of an optimal mature size.

\section{Materials and Methods}

A number of production region classification systems for South Africa were reviewed and the Bioregion classification type was deemed the most suitable for use as a beef production region classification system for the purpose of this study. The geographic locations of the larger Bonsmara farmers were identified for this study. Geographic Information System (GIS) analysis was used to link the location of individual Bonsmara cattle farms with the bioregion in which Bonsmara herds are located, as well as the performance records of individual cows on each farm. Bonsmara herds located in the Central bushveld-, Eastern Kalahari bushveld-, Dry Highveld grassland-, and Mesic Highveld grassland bioregions, as defined by VEGMAP of Mucina \& Rutherford (2006), were included in the study. Animal records were included from the year 1990 to 2010 .

Data included in the analyses were that of Bonsmara farmers who had records for mature cow weight (weight of cows at ca. 48 months of age) for at least 50 cows that were raised on location and whose performance fell within industry accepted norms. A total of 12549 cow records from 73 Bonsmara farmers were used in the final data analysis. Animal production records used in this study were obtained from the June 2010 BLUP evaluation file from the South African National Beef Recording and Improvement Scheme (SANBRIS). SANBRIS is managed by the Animal Production Institute of the Agricultural Research Council 
(ARC) on behalf of the Department of Agriculture, Forestry and Fisheries (DAFF). The file contained pedigree and production records for 1468502 Bonsmara cattle collected since 1949. Production and reproduction measurements and estimated breeding values (EBVs) that were recorded and calculated by SANBRIS for each individual animal were included in the data file. The EBVs published by SANBRIS are derived from mixed model breeding values that remove the environmental influence in order to predict the additive genetic merit of the animal (Hunlun, 2011).

The focus of this study was on the environmental $(E)$ component rather than the phenotypic $(P)$ or genotypic $(G)$ values. The method followed to derive E-values was as follows: The phenotype $(P)$ of an animal is the result of its genotype $(G)$ inherited from its parents and the environmental influence. It is mathematically described as: $P=G+E$

The $G$ is the sum of the additive and non-additive genetic components, while $E$ consists of both the known and unknown environmental effects (Falconer \& Mackay, 1996). In the case of this study $E$ was calculated as $E=P$ - EBV.

E-values were calculated for all traits; for example, a cow with a mature weight (MW) P value of 505 $\mathrm{kg}$ and EBV or additive genetic component of $+5.5 \mathrm{~kg}$, will have a MW_E value of $499.5 \mathrm{~kg}$. In the assumption that environmental effects can be deducted from the calculation of $P$ from $P=G+E$, the breeding structure of the Bonsmara breed, as described by Hunlun (2011), and an acceptable degree of pedigree depth and ratios between breeder herds and multiplier herds, as well as the typical pyramid breeding structure in the breed, conform to the theoretical and investigative findings of Hill et al. (2008), negating the effects of non-additive gene actions in recorded differences among animals. The non-additive genetic effects not accounted for in this assumption should, therefore, be negligible and of little consequence in the findings of this study. However, in interpreting the results, it should be kept in mind that the nonadditive effects are included in $\mathrm{E}$.

Statistical analysis of the 12549 records that remained after data editing, was done by means of the general linear method (GLM) procedure of $S A S^{\circledR}$ version 9.2 in MS/WINDOWS XP Professional (SP3). A cluster analysis was performed on the median of MW_E and reproduction index $(R I=200$ - (( (age at last calving in days/(966 + (417 $\times$ (number of calving's -1$))) \times 100)$ per Bonsmara farm, using Proc Cluster and the results visualised using Proc Cluster Tree. The geographic location of each Bonsmara farmer in every cluster was then graphically depicted on a map of South African by means of Maptitude 4.5 software. To investigate the influence of Bonsmara farm and bioregion on the growth variables (birth weight (BW_E), weaning weight (WW_E), 12-month old weight (12 MW_E), 18-month old weight (18 MW_E), size (MW_E), and reproduction traits (age at first calving (AFC_E), inter calving period (ICP_E) and reproduction index (RI)) an ANOVA was performed using PROC GLM with the least square means (LSM) option, at a significance level of $95 \%(P \leq 0.05)$ for the critical values of the F-statistic. Standard error of the means (SE) was also investigated.

The dataset was then filtered to remove any growth, size, or reproduction trait measurements and or environmental characteristics of less than or larger than three standard deviations (SD) from the mean of each respective variable within bioregions, in an attempt to normalize the data. MW_E and RI were not filtered, as they were filtered in the first round of data preparation. Although this reduced the size of the dataset from 12549 records to 5520 records, the results of the stepwise regression remained relatively unchanged and the $\mathrm{R}^{2}$ (goodness of fit) values of the models improved slightly.

Cluster analysis was performed to investigate the effect of geographic location (bioregion) on Bonsmara cow size. Bonsmara farms (herds) were clustered by means of Proc Cluster according to the median herd MW_E. This was followed by stepwise regression analyses by employing the Proc Reg (SLstay) function with the growth variables- (birth weight (BW_E), weaning weight (WW_E), 12-month old weight (12 MW_E), 18-month old weight ((18 MW_E), (size- (MW_E)), and reproduction traits (age at first calving (AFC_E), inter calving period (ICP_E) and reproduction index (RI)) as dependent variables and the environmental characteristics (temperature, rainfall, soil $\mathrm{P}$, soil $\mathrm{pH}$, soil carbon content, cation exchange capacity (CEC) and grazing capacity) as independent variables.

\section{Results and Discussion}

Summary statistics of the production traits of Bonsmara cows based on data for the period from 1990 to 2010 are presented in Table 1. Bonsmara herds that complied with the criteria for this study were located mostly in the central and north-eastern parts of the country. In terms of mature cow size, there were four main clusters of Bonsmara herds with a distance of ca. 0.8 between the cluster centroids (Table 2). Cluster analysis results are presented graphically in Figure 1. Although MW_E medians of cow herds grouped into clusters 4 and 7 were numerically lower than those grouped into clusters 5 and 6 (Table 2), no objective conclusion regarding the influence of geographic location on Bonsmara cow size could be made from the cluster analysis results. 
Table 1 Summary statistics of the production traits of Bonsmara cows in South Africa (1990 to 2010)

\begin{tabular}{lcccccc}
\hline Traits & N & Mean & S.D & S.E.M & Median & Mode \\
\hline BW_E (kg) & 12185 & 34.3 & 3.4 & 9.9 & 34.3 & 38.0 \\
WW_E (kg) & 12549 & 214.7 & 31.3 & 14.6 & 214.7 & 252.2 \\
12 MW_E (kg) & 11524 & 254.6 & 39.4 & 0.4 & 253.8 & 166.7 \\
18 MW_E (kg) & 9689 & 329.1 & 45.8 & 0.5 & 328.3 & 255.9 \\
MW_E (kg) & 12549 & 499.5 & 54.4 & 0.5 & 498.6 & 568.5 \\
AFC_E (days) & 12549 & 963.9 & 115.9 & 1.0 & 954.7 & 715.0 \\
ICP_E (days) & 9016 & 422.8 & 62.3 & 0.7 & 407.7 &. \\
RI (\%) & 12549 & 104.6 & 8.9 & 0.1 & 105.8 & 96.7
\end{tabular}

S.D. = Standard deviation; S.E.M. = Standard error of the mean, BW_E = Environmental component of birth weight; WW_E = Environmental component of wean weight; $12 \mathrm{MWE}=$ Environmental component of 12-month weight; 18 $\mathrm{MW} \_\mathrm{E}=$ Environmental component of 18 -month weight; $\mathrm{MW}$ E $=$ Environmental component of mature weight; AFC_E = Environmental component of age at first calving; $I C P \_E=$ Environmental component of inter-calving period; $\bar{R} I=$ Reproduction index

Table 2 Summary of cluster contents of Bonsmara herds included in the study based on the environmental component of mature weight of cows (MW_E)

\begin{tabular}{lcccc}
\hline Cluster \# & \# Animals & \# Herd & Median & Distance \\
\hline Cluster 4 & 429 & 5 & $427.4 \mathrm{~kg}$ & 0.81 \\
Cluster 7 & 3600 & 20 & $471.0 \mathrm{~kg}$ & 0.50 \\
Cluster 6 & 7751 & 40 & $509.6 \mathrm{~kg}$ & 0.53 \\
Cluster 5 & 769 & 8 & $550.7 \mathrm{~kg}$ & 0.61 \\
\hline
\end{tabular}

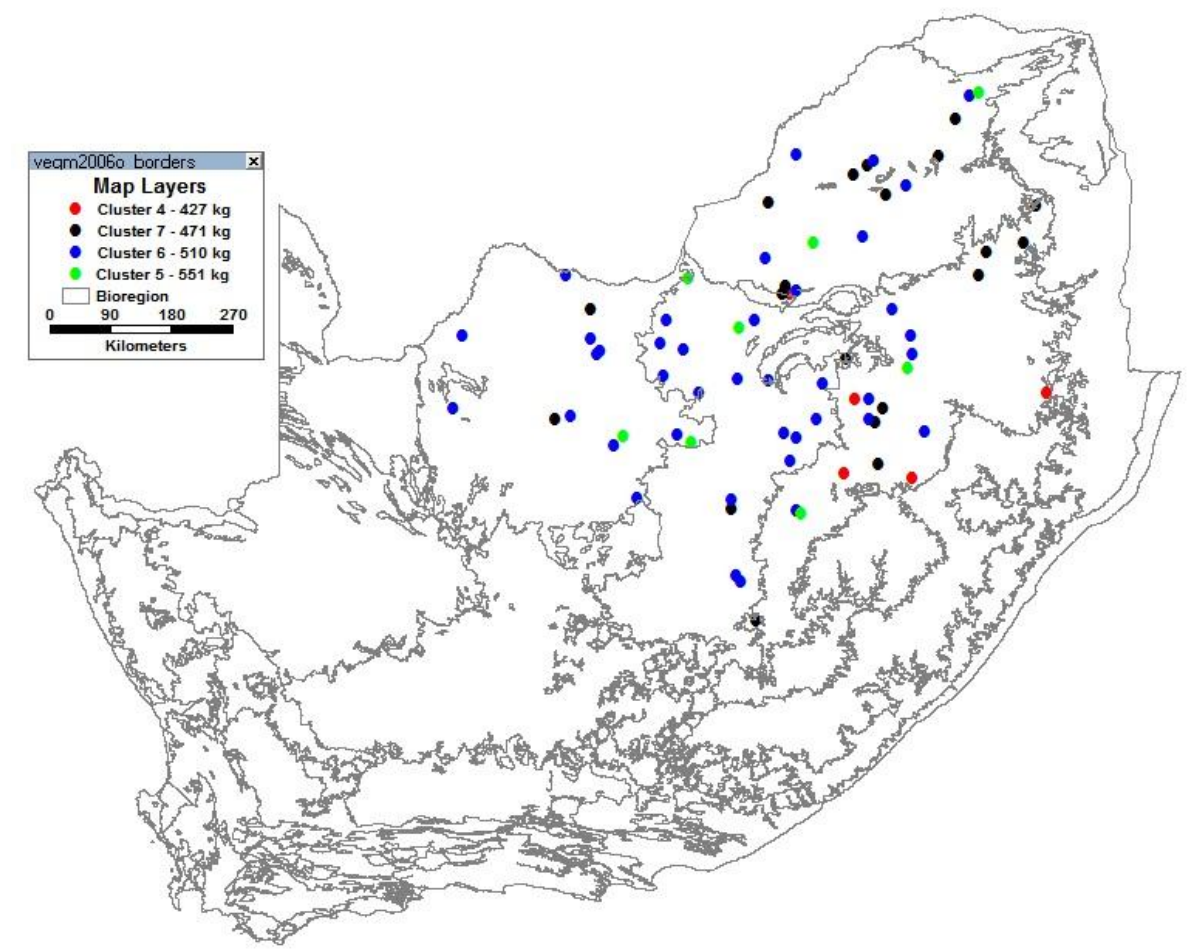

Figure 1 Geographic locations of the cluster component Bonsmara herds 
The effects of bioregion on growth and size traits of Bonsmara cows are presented in Table 3 while the effects on reproduction traits are presented in Table 4. Analysis of variance (ANOVA) results indicate that there were differences $(P<0.05)$ between bioregions in terms of the environmental components of growth traits, notably birth weight (BW_E), weaning weight (WW_E), 12-month weight (12 MW_E), 18-month weight (18 MW_E) and mature weight (MW_E) of Bonsmara cows. The latter confirms the notion about regional differences in growth traits and cow size, since cows in the Central bushveld and Mesic Highveld grassland were smaller $(P<0.05)$ than those in the Dry Highveld grassland and Eastern Kalahari bushveld. Similarly ANOVA results indicate differences between bioregions $(P<0.05)$ in terms of the environmental components of reproduction traits, namely age at first calving (AFC_E), inter-calving period (ICP_E), as well as reproduction index (RI).

Table 3 Effects of bioregion on growth and size traits (Least square means and standard errors (S.E)) of Bonsmara cows in South Africa from 1990 to 2010

\begin{tabular}{lcccccc}
\hline Bioregion & N & BW_E (kg) & WW_E (kg) & 12 MW_E(kg) & 18 MW_E(kg) & MW_E (kg) \\
\hline Central bushveld & 2366 & $34.0(0.07)^{\mathrm{a}}$ & $206.9(0.62)^{\mathrm{a}}$ & $249.8(0.81)$ & $319.8(1.00)^{\mathrm{a}}$ & $494.3(1.10)^{\mathrm{a}}$ \\
Dry Highveld grassland & 2472 & $34.5(0.07)^{\mathrm{b}}$ & $216.5(0.60)^{\mathrm{b}}$ & $261.2(0.79)$ & $332.4(1.06)^{\mathrm{b}}$ & $512.3(1.08)^{\mathrm{b}}$ \\
Eastern Kalahari bushveld & 3747 & $34.7(0.06)^{\mathrm{b}}$ & $227.2(0.49)^{\mathrm{b}}$ & $266.1(0.64)$ & $340.3(0.85)^{\mathrm{b}}$ & $506.3(0.87)^{\mathrm{b}}$ \\
Mesic Highveld grassland & 3964 & $33.9(0.05)^{\mathrm{a}}$ & $206.5(0.48)^{\mathrm{a}}$ & $241.4(0.65)$ & $322.9(0.82)^{\mathrm{a}}$ & $488.1(0.85)^{\mathrm{a}}$
\end{tabular}

$\overline{a, b}$ Least Square Means in the same column with different superscript letters differ $(P<0.05)$

BM_E = Environmental component of birth weight; WM_E = Environmental component of weaning weight; $12 \mathrm{MW} E=$ Environmental component of 12 month weight; $18 \mathrm{MW}$ _E = Environmental component of 18 month weight; $\mathrm{MW}$ - E = Environmental component of mature cow weight

Table 4 Effect of bioregion on reproduction traits (Least square means and standard errors (SE)) of Bonsmara cows in South Africa based on data from 1990 to 2010

\begin{tabular}{lcccc}
\hline Bioregion & $\mathbf{n}$ & AFC_E (days) & ICP_E (days) & RI (\%) \\
\hline Central bushveld & 2366 & $980.3(2.34)^{\mathrm{a}}$ & $420.5(1.51)^{\mathrm{a}}$ & $103.5(0.18)^{\mathrm{a}}$ \\
Dry Highveld grassland & 2472 & $958.0(2.29)^{\mathrm{b}}$ & $412.7(1.44)^{\mathrm{b}}$ & $106.2(0.17)^{\mathrm{b}}$ \\
Eastern Kalahari bushveld & 3747 & $935.1(1.86)^{\mathrm{b}}$ & $418.1(1.15)^{\mathrm{bc}}$ & $106.8(0.14)^{\mathrm{b}}$ \\
Mesic Highveld grassland & 3964 & $985.2(1.81)^{\mathrm{a}}$ & $436.4(1.20)^{\mathrm{ac}}$ & $102.1(0.14)^{\mathrm{a}}$ \\
& & & \\
a,b,c Least Square Means in the same column with different superscript letters differ (P<0.05). AFC_E = Environmental $_{\text {component of age at first calving; ICP_E = Environmental component of inter calving period; RI = Reproduction index (\%) }}$
\end{tabular}

A summary of the correlation coefficients $\left(R^{2}\right)$ for the effects of bioregion and Bonsmara farm on production and reproduction traits of cows is presented in Table 5. The ANOVA results indicate that there were significant $(P<0.05)$ differences between bioregions for most of the production traits. The amount of variation in production traits explained by bioregion differed from $10 \%$ for early life traits such as BW and WW, to between $5 \%$ and $6 \%$ for traits measured later in life such as $18 \mathrm{MW}, \mathrm{MW}, \mathrm{AFC}$ and ICP. In large datasets it is often difficult to determine the biological versus the statistical importance of interactions, as some interactions are statistically significant, but with little biological importance (Burfening et al., 1987). ANOVA results indicated that both bioregion $(P<0.05)$ and Bonsmara farm $(P<0.0001)$ influenced cow production traits.

Results of stepwise regression analyses are shown in Table 6. Regression analyses were used to compare the direction and size of the contribution of different environmental characteristics across models. Although the coefficients from different linear models are not comparable, the tendencies were assessed. An across-model comparison revealed that temperature had a significantly $(P<0.0001)$ negative correlation with all growth, size and reproduction traits, except for BW_E. The negative effects of temperature was expected and coincides with results of previous studies which emphasized the adverse effects of temperature and in particular heat stress (Bonsma, 1983; Du Preez et al., 1992) on animal production and reproduction traits. 
Heat stress occurs when environmental variables such as ambient temperature, humidity, air movement and solar radiation combine to reach values that surpass the upper limit of the thermo-neutral zone (Bernabuccil et al., 2010). Heat-stressed animals tend to decrease their feed intake and rumination time, resulting in a decrease in nutrient intake (Collier et al., 2005), which may result in a negative energy balance (Bernabuccil et al., 2010). Heat stress also results in an altered endocrine status that increases maintenance requirements (Collier et al., 2005).

Table 5 Summary of the correlation coefficients ( $R^{2}$ values) for the effects of Bonsmara farm and bioregion on production and reproduction traits of Bonsmara cows as calculated from data from 1990 to 2010

\begin{tabular}{lcc}
\hline & \multicolumn{2}{c}{ Correlation coefficient $\left.\mathbf{( R}^{\mathbf{2}}\right)$} \\
\cline { 2 - 3 } Trait & Bonsmara farm & Bioregion \\
\hline BW_E & 0.12 & 0.01 \\
WW_E & 0.21 & 0.08 \\
12 MW_E & 0.30 & 0.07 \\
18 MW_E & 0.24 & 0.03 \\
MW_E & 0.26 & 0.03 \\
AFC_E & 0.23 & 0.03 \\
ICP_E & 0.16 & 0.02 \\
RI & 0.22 & 0.05
\end{tabular}

BW_E = Environmental component of birth weight; WW_E $=$ Environmental component of weaning weight; $12 \mathrm{MW} E=$ Environmental component of 12-month weight; $18 \mathrm{MW}$ E = Environmental component of 18-month weight; MW_E = Environmental component of mature weight; $A F C E=$ Environmental component of age at first calving; $I C P$ E = Environmental component of inter-calving period; $\mathrm{RI}=$ Reproduction index

The negative relationship between temperature and the growth and size traits are therefore due to the depressing influence that high environmental temperatures have on the energy status of cows. The biological mechanisms responsible for the negative influence of heat stress on female reproduction are not completely understood (Rhoads et al., 2009). The influence of temperature on production traits was significant $(P$ $<0.0001$ ), and these effects on production traits are quite notable if one considers the subsequent changes in weight as estimated from the parameter estimates (b-values) following a $1{ }^{\circ} \mathrm{C}$ increase in temperature. Similarly temperature had a significant effect on the reproductive ability of Bonsmara cows, with both AFC_E and ICP_E increasing $(P<0.01)$ and $\mathrm{RI}$ decreasing $(P<0.01)$ with an increase in temperature. The current data indicates that although Bonsmara cows are generally well managed, temperature has a significant effect on production and reproduction traits of Bonsmara cows.

Rainfall also had a significant $(P<0.0001)$ negative impact on all growth, size and reproduction traits of Bonsmara cows. Regression analysis indicate that higher rainfall resulted in a decrease in BW_E, 18 MW_E, MW_E $(P<0.05)$, and an increase in $\mathrm{RI}(P<0.05)$. The relationship between rainfall and growth in the present study agrees with the findings of Neser et al. (2008), who reported that rainfall explained $10 \%$ of the weaning weight of Bonsmara weaner calves. Fynn \& O'Conner (2000) also found a curvilinear relationship between rainfall and cattle production.

It is accepted that rainfall has a large influence on the quantity and quality of forage (Snyman, 1999; Tainton \& Hardy, 1999; Fynn \& O'Conner, 2000). The negative relationship between rainfall and cattle production traits can be explained based on the traditional South African sweet-, mixed-, and sourveld classification system (Snyman, 2012). The latter classification system refers to the period of the year in which the natural grazing can sustain animal production without supplementation (Tainton \& Hardy, 1999). Sweetveld is the most nutritious throughout the year and generally occurs in areas that receive $200-500 \mathrm{~mm}$ of rainfall (Van Rooyen, 2002; Snyman, 2012). Sourveld become unacceptable and less nutritious after maturity and generally occurs in areas that receive a higher rainfall, e.g. at least $650 \mathrm{~mm}$ per annum (Van Rooyen, 2002; Snyman, 2012). There is a general tendency for the nutritional value of South Africa's forage 
Table 6 Stepwise regression results indicating the effects of environmental and non-additive genetic factors on production traits of Bonsmara cows

\begin{tabular}{|c|c|c|c|c|c|c|c|c|c|c|c|c|c|c|c|c|}
\hline \multirow{3}{*}{ Traits } & \multirow{3}{*}{ Intercept } & \multicolumn{15}{|c|}{ Model } \\
\hline & & \multicolumn{2}{|c|}{ Temperature } & \multicolumn{2}{|c|}{ Rainfall } & \multicolumn{2}{|c|}{ Phosphorus } & \multicolumn{2}{|c|}{ Soil pH } & \multicolumn{2}{|c|}{ Soil Organic Carbon } & \multicolumn{2}{|c|}{ Cation Exchange Capacity } & \multicolumn{2}{|c|}{ Grazing Capacity } & \multirow{2}{*}{$\mathbf{M}-\mathbf{R}^{2}$} \\
\hline & & P-est & $\mathbf{P}-\mathbf{R}^{2}$ & P-est & $\mathbf{P}-\mathbf{R}^{2}$ & P-est & $\mathbf{P}-\mathbf{R}^{2}$ & P-est & $\mathbf{P}-\mathbf{R}^{2}$ & P-est & $\mathbf{P}-\mathbf{R}^{2}$ & P-est & $\mathbf{P}-\mathbf{R}^{2}$ & P-est & $\mathbf{P}-\mathbf{R}^{2}$ & \\
\hline \multicolumn{17}{|c|}{ Growth traits } \\
\hline BW_E & 39.97 & 0.09 & 0.02 & -0.01 & $<0.01$ & -0.20 & $<0.01$ & - & - & 0.30 & $<0.01$ & -0.04 & $<0.01$ & -0.20 & $<0.01$ & 0.04 \\
\hline WW_E & 261.43 & -0.78 & $<0.01$ & -0.07 & 0.08 & - & - & 2.69 & $<0.01$ & - & - & -0.41 & $<0.01$ & - & - & 0.09 \\
\hline $12 \mathrm{MW} E \mathrm{E}$ & 363.88 & -1.72 & $<0.01$ & -0.08 & 0.09 & - & - & -3.12 & $<0.01$ & -14.10 & $<0.01$ & 0.72 & $<0.01$ & 0.55 & $<0.01$ & 0.10 \\
\hline 18 MW_E & 401.58 & -1.51 & $<0.01$ & -0.06 & 0.04 & - & - & 1.99 & $<0.01$ & -11.98 & $<0.01$ & - & - & - & - & 0.05 \\
\hline MW_E & 699.41 & -1.33 & $<0.01$ & -0.20 & 0.02 & -4.30 & 0.01 & 4.18 & $<0.01$ & -14.83 & 0.03 & - & - & -4.56 & 0.01 & 0.07 \\
\hline \multicolumn{17}{|c|}{ Reproduction traits } \\
\hline AFC_E & 219.54 & 15.29 & 0.01 & 0.34 & 0.02 & 12.72 & 0.01 & - & - & 45.11 & 0.03 & 2.85 & $<0.01$ & 1.83 & $<0.01$ & 0.07 \\
\hline ICP_E & 120.68 & 2.01 & $<0.01$ & 0.30 & 0.01 & 4.75 & $<0.01$ & - & - & -16.65 & 0.01 & 2.81 & 0.01 & 4.97 & 0.01 & 0.05 \\
\hline RI & 159.89 & -0.52 & 0.01 & -0.05 & 0.04 & -1.29 & 0.02 & 0.54 & $<0.01$ & 1.71 & $<0.01$ & -0.40 & 0.01 & -0.76 & 0.02 & 0.10 \\
\hline
\end{tabular}

All regression models were significant with $P<0.0001$

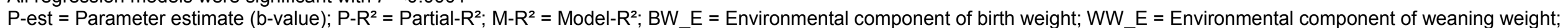
$12 \mathrm{MW} \_\mathrm{E}=$ Environmental component of 12-month weight; $18 \mathrm{MW} \_\mathrm{E}=$ Environmental component of 18-month weight; MW_E = Environmental component of mature cow weight; AFC_E = Environmental component of age at first calving; ICP_E = Environmental component of inter-calving period; RI = Reproduction index 
to decline during winter in higher rainfall areas. The negative relationship between rainfall and Bonsmara cow production traits was probably due to the influence that rainfall has on the nutritional value of forage and consequently nutrient intake.

Results indicate that soil $\mathrm{P}$ had a significantly $(P<0.0001)$ negative relationship with $\mathrm{BW} \_\mathrm{E}, \mathrm{MW} E$, and reproduction traits. These results are surprising since the implication is that an increased soil $\mathrm{P}$ level is associated with a decrease in BW_E, MW_E, and reproductive efficiency of Bonsmara cows. It is well known that P-deficiency is associated with subnormal growth and fertility (McDonald et al., 2002), while numerous studies have shown that P-supplementation has a major positive impact on the growth, size (Read et al., 1986; De Waal et al, 1996; De Brouwer et al., 2000), and reproduction (Read et al., 1986; De Waal et al, 1996; Orsmond, 2007) of beef cattle in South Africa. Large areas of South Africa are deficient in P (Du Toit et al., 1940; Meissner, 1999), and, therefore, a positive relationship between $P$ and production traits of Bonsmara cows was expected. However, P-supplementation is widely given to grazing cattle in South Africa (De Waal et al, 1990). The present results suggest that P-supplementation is effective in P-deficient areas, but that P-supplementation in areas with marginal and adequate soil $\mathrm{P}$-levels may require more $\mathrm{P}$ supplementation to remedy marginal deficiencies.

Soil pH had a significantly $(P<0.0001)$ positive relationship with WW_E, 18 MW_E, MW_E, and RI, which implies that a lower soil $\mathrm{pH}$ (more acidic) had a negative influence on most of the production traits of Bonsmara cows. Soils with a lower $\mathrm{pH}$ are generally associated with higher rainfall areas (Brady \& Weil, 2002). It was previously shown that higher rainfall had a negative impact on cow production traits. The relationship between soil $\mathrm{pH}$ and Bonsmara production traits may, therefore, be due to an indirect influence of rainfall on feed quality. The relationship between $\mathrm{pH}$ and $12 \mathrm{MW}$ _E was weak and negative, which may be due to retarded growth responses of Bonsmara heifers typically due to post weaning shock exhibited from 7 to 12 months of age.

Results indicate that soil organic carbon content exhibited a significant $(P<0.0001)$ negative relationship with $12 \mathrm{MW} E$, $18 \mathrm{MW}$ EE, MW_E, and AFC_E, but significantly $(P<0.0001)$ positive correlations between soil organic carbon content and $B \bar{W} \_E, R I$, and ICP_E. The influence of soil organic carbon on cow production traits is ambiguous. Cation exchange capacity (CEC) showed a significant $(P<0.0001)$ negative relationship with $B W \_E, W W \_E$, but positive relationship with $12 \mathrm{MW} E$, which suggests that calves are partially buffered in utero and during lactation against low CEC. However, the overall contribution of CEC to growth traits of Bonsmara cows was small but significant (partial $R^{2}<0.01$ ), which implies a small biological effect on the growth of Bonsmara cows. Soil with high CEC has a greater ability to retain its nutrient cations and is consequently more fertile (Whitehead, 2000), but the absence of any meaningful effect of CEC on the growth traits of Bonsmara cows suggest efficient nutrient supplementation and management on Bonsmara farms.

Grazing capacity exhibited a negative correlation $(P<0.0001)$ with BW_E, 12 MW_E and MW_E, which agrees with previous negative correlations between rainfall and Bonsmara growth parameters. Bioregions with higher rainfall exhibited a higher quantity of grazing but of lower nutrient quality and often with nutrient deficiencies. The positive correlation $(P<0.0001)$ between grazing capacity and $12 \mathrm{MW} E$ coincides with the effects observed for soil $\mathrm{pH}$ and post weaning shock in young Bonsmara heifers, with subsequent compensatory growth responses at about 12 months of age as previously explained. Grazing capacity also correlated negatively with Bonsmara reproduction traits, again due to the effects of rainfall (Fourie, 1985), species composition and, therefore, veld condition (Snyman, 2012). It follows that the relationship between grazing capacity and growth traits of Bonsmara cows may also be related to indirect effects of rainfall.

The combined effects of all the environmental factors studied in this research on Bonsmara cow production traits ranged from $4 \%$ for BW_E, $9 \%$ for WW_E, 10\% for $12 \mathrm{MW} \_$E, $5 \%$ for $18 \mathrm{MW}$ _E, and $7 \%$ for MW_E. Collectively the environmental effects explained about $7 \%$ of the variation in AFC_E, $5 \%$ of ICP_E and $10 \%$ of RI. The results confirm that the extent of the effects of the measured environmental factors on growth and reproduction traits of Bonsmara cows depend on the physiological stage of growth and reproduction, which agrees with the original findings of Fitzhugh et al. (1967) in this regard. For example, the effects of the environmental factors on birth weight was small (4\%), due to the known buffering effect of the intra uterine environment to ensure optimal growth of the developing neonatal calf in utero. By contrast, the external environment had a statistically and biologically larger influence on weaning- $(9 \%)$ and yearling weights $(10 \%)$ of Bonsmara heifers, compared to early growth traits. These blunted environmental effects at birth and up to weaning were also partly due to common management practices employed by farmers such as the use of summer calving season and early winter weaning, so that weaners are raised on late winter and early spring grazing. Rainfall had a negative impact on heifer weight at weaning and yearling age due to its influence on the quality of grazing in terms of available nutrient content. These results indicate that nutritional supplementation prior to weaning until post yearling age has the greatest potential to improve the 
production efficiency of extensively managed Bonsmara cows in the higher rainfall (sour veld) areas of South Africa.

Once Bonsmara heifers became adapted and mature enough to reproduce (e.g. 18 months of age) the environment had an increasingly smaller $(5 \%)$ influence on their growth. It is conceded that benefits of calving, weaning, growth and reproduction to coincide mostly with spring and summer for optimum feed quantity and quality, as well as on-farm management practices also lessened the effects of some of the environmental factors studied. The influence of environmental factors studied in this research on Bonsmara cow size was large $(7 \%)$ as expected, because the mature cows have been exposed to their prevailing bioregion for an extended period of time, with subsequent effects on reproduction efficiency. Environments that ensured better early growth until mating, improved AFC (7\%) and decreased ICP (5\%). ICP is a complex trait that is influenced by numerous intrinsic and extrinsic factors, but the underlying causal mechanisms remain unclear. The effect of the combined environment on $\mathrm{RI}$ was larger $(10 \%)$ than on $\mathrm{AFC}$ or ICP, because $\mathrm{RI}$ is a combination of a cow's AFC and ICP.

\section{Conclusions}

It is concluded that production region (bioregion) had a small but significant effect on the production and reproduction efficiency of Bonsmara cows, which supports the concept of a geographic influence on cow size and, therefore, an optimum cows size in each livestock production region of South Africa. Results indicate that both bioregion and Bonsmara farm influenced production and reproduction efficiency of cows. Bonsmara farm effects were probably due to the implementation of management practices and the breeding philosophy of the Bonsmara cattle Breeders Society of South Africa. However, the possible effect on nongenetic effects was not eliminated in this study. Environmental factors, and possibly non-additive genetic effects influenced all production traits measured for Bonsmara cows, with rainfall and temperature being most significant. The extent of the effects of the combined influences of environmental factors and nongenetic effects on cow productivity depended on the physiological stage of animal growth and reproduction. Environmental and non-genetic effects on the production efficiency of Bonsmara cows were buffered by maternal effects at birth, but became more significant after weaning (9\%) to yearling age (10\%) and maturity. Bonsmara heifer weights were affected most at weaning- and yearling age, by rainfall. The negative correlation between rainfall and production traits was associated with the adverse effects of rainfall on forage quality and nutrient availability through effects on soil $\mathrm{pH}$, soil phosphorus and organic carbon content. Temperature had a negative impact on the growth, size, and reproduction traits of Bonsmara cows, with the exception of birth weight, which was buffered by the intra-uterine environment.

\section{Acknowledgements}

The authors thank the Agricultural Research Council (ARC, Irene) for their assistance with the BLUP evaluation file from the South African National Beef Recording and Improvement Scheme.

\section{Authors' Contributions}

The study was conceived by ECW, based on the MSc dissertation of PCV, which was produced under the supervision of ECW, JvdW and HAS. The original manuscript was drafted by PCV, but a comprehensive revision was done and submitted by ECW.

\section{Conflict of Interest Declaration}

The authors declare that they have no conflicts of interest with regard to this work.

\section{References}

Arango, J.A. \& Van Fleck, L.D. 2002. Size of beef cows: early ideas, new developments. Genet. Mol. Res. 1, 51-61.

Bernabuccil, U., Lacetera, N., Baumgard, L.H., Rhoads, R.P., Ronchi, B. \& Nardone, A. 2010. Metabolic and hormonal acclimation to heat stress in domesticated ruminants. Animal 4, 1167-1183.

Bonsma, J.C. 1983. Man must measure: Livestock Production. Agi Books, Cody, W.Y., USA.

Brady, N.C. \& Weil, R.R. 2002 . Soil acidity. In: The nature and properties of soils, 13th edition. New Jersey: Prentice Hall.

Burfening P.J., Kress, D.D. \& Hanford K. 1987. Effect of region of the United States and age of dam on birth weight and 205-d weight of Simmental calves. J. Anim. Sci. 64, 955-962.

Buttram, S.T. \& Willham, R.L. 1989. Size and management effects on reproduction in first-, second-, and third-parity beef cows. J. Anim. Sci. 67, 2191-2196.

Collier, R.J., Baumgard, L.H., Lock, A.L. \& Bauman, D.E. 2005. Physiological limitations, nutrient partitioning. In: Yield of farmed species. Constraints and opportunities in the 21st Century. Eds. Sylvester-Bradley, R. \& Wiseman, J. Nottingham, UK: Nottingham University Press.

De Brouwer, C.H.M., Cilliers, J.W., Vermaak, L.M., Van der Merwe, H.J. \& Groenewald, P.C.N. 2000. Phosphorus supplementation to natural pasture grazing for beef cows in the Western Highveld region of South Africa. S. Afr. J. Anim. Sci. 30(1), 43-52. 
De Jager, J.M., 1993. Geographic and agro-ecological features of Southern Africa. In: Livestock Production systems Principles and Practice. Ed. Maree, C. \& Casey, N.H. Pretoria: Agri Development Foundation, South Africa.

De Waal, H.D. 1990. Animal production from native pasture (veld) in the Free State region. A perspective of the grazing ruminant. S. Afr. J. Anim. Sci. 20, 1-9.

De Waal, H.O., Randall, J.H.R. \& Koekemoer, G.J. 1996. The effects of phosphorus supplementation on body mass and reproduction of grazing beef cows supplemented with different levels of phosphorus at Armoedsvlakte. S.Afr. J. Anim. Sci. 26(2), 29.

Du Preez, J.H., Giesecke, W.H., Barnard, M.L., Erasmus, A.G., Hatting, P.J., Eisenburg, B.E., Willemse, J.J.C. \& Kruger, R. 1992. Heat stress on dairy cattle and other livestock under South African conditions. Tech. comm. Dept. Agric. Dev. Repub. S. Afr.

Du Toit, P.J., Louw, J.A. \& Malan, A.I. 1940. A study of the mineral content and feeding value of natural pastures in the Union of South Africa. Onderstepoort. J. Vet. Sci. 14, 123.

Echols, A.C. 2011. Relationships among lifetime measures of growth and frame size for commercial beef females in a pasture-based production system in the Appalachian region of the United States. MSc Thesis. Virginia Polytechnic Institute and State University.

Falconer, D.S. \& Mackay, T.F.C. ,1996. Introduction to quantitative genetics. Harlow, UK: Longman.

Fitzhugh, H.A., Cartwright, T.C. \& Temple R. S. 1967. Genetic and environmental factors affecting weight of beef cows. J. Anim. Sci. 26, 991-1001.

Fourie, J.H. 1985. Die invloed van veebelading op veeproduksie en veldtoestand. Glen Agric. 14, 8-11.

Fynn, R.W.S. \& O'Conner, T.G. 2000. Effect of stocking rate and rainfall on rangeland dynamics and cattle performance in a semi-arid savanna. S. Afr. J. Appl. Ecol. 37, 491-507.

Hafez, E.S.E. 1968. Principles of animal adaptation. In: Adaptation of domestic animals. Eds. Hafez, E.S.E. Philadelphia: Lea \& Febiger.

Hunlun C., 2011. The analysis of breeding structure in the modern context. Applied Animal Husbandry \& Rural Development,4, 14-21.

Johnson, J.J., Dunn, B.H. \& Radakovich, J.D. 2010. Understanding cow size and efficiency. Proc. $42^{\text {nd }}$ Beef Improvement Fed. Conf. pp. 62-70.

Leighton, E.A., Wilham, R.L. \& Berger, P.J. 1982. Factors influencing weaning weights in Hereford cattle and adjustment factors to correct records for these effects. J. Anim. Sci. 54, 957.

Maptitude GIS Software, Version 4.5., Caliper Corporation, Newton, Massachusetts, United States of America.

McDonald, P., Edwards, R.A., Greenhalgh, J.F.D. \& Morgan, C.A. 2002. Grass and Forage Crops. In: Animal Nutrition. Eds. McDonald, P., Edwards, R.A., Greenhalgh, J.F.D. \& Morgan, C.A. 6th edition, Essex: Pearson Education limited.

Meissner, H.H. 1999. Nutrient supplementation of the grazing animal. In: Veld management in South Africa Ed. Tainton, N.M. Pietermaritzburg: University of Natal Press, South Africa.

Mucina, L. \& Rutherford, M.C. 2006. The vegetation of South Africa, Lesotho and Swaziland. Pretoria: Strelitzia 19. South African National Biodiversity Institute.

Neser, F.W.C., Erasmus, G.J. \& Scholtz, M.M. 2008. The use of a cluster analysis in across herd genetic evaluation for beef cattle. S. Afr. J. Anim. Sci. 38(1), 51-57.

Orsmond, M. 2007. The influence of phosphorus supplementation on growth and reproduction characteristics of beef cows in the semi-arid Bushveld of South Africa. M.Sc (Agric) Thesis. University of Pretoria, Pretoria, South Africa.

Read, M.V.P., Engels, E.A.N. \& Smith, W.A. 1986. Phosphorus and the grazing ruminant. 2. The effects of supplementary P on cattle at Glen and Armoedsvlakte. S. Afr. J. Anim. Sci. 16, 6-12.

Rhoads, M.L., Field, S.E., Cossel, S.E., Wheelock, J.B., Collier, R.J., Rhoads, R.P. \& Baumgard, L.H. 2009. Metabolic adaptations to heat stress and related effects on fertility. Proc. 24th Annual South West Nutr. \& Mgmnt. Conf. 147.

Ronchietto, P.C. 1993. The effect of agro-ecological regions on beef production in Natal. M.Sc. (Agric) Thesis. University of Pretoria. Pretoria.

SAS, 2008. Statistical Analysis Systems user's guide (Statistics Version 9.2). SAS Institute Inc. Cary, North Carolina, USA.

Scholtz, M.M. 2010. Beef Breeding in South Africa. 2nd edition, Pretoria: Agricultural Research Council, South Africa.

Scholes, R.J.S. 1990. The influence of soil fertility on the ecology of southern African dry savannas. J. Biogeogr. 17, 415419.

Schulze, R.E. 1997. Climate. In: Vegetation of Southern Africa, Eds. Cowling et al., Cambridge: Cambridge University Press.

Snyman, H.A. 1998. Dynamics and sustainable utilisation of rangeland ecosystems in arid and semi-arid climates in southern Africa. J. Arid. Environ. 39, 645-666.

Snyman, H.A. 1999. Quantification of the soil-water balance under different veld condition classes in a semi-arid climate. Afr. J. Range Forage. Sci. 16, 108-117.

Snyman, H.A. 2009. Root studies on grass species in a semi-arid South Africa along a degradation gradient. Agric. Ecosyst. Environ 130, 100-108.

Snyman, H. A. 2012. Veldbestuurspraktyke. In: Gids tot die volhoubare produksie van weiding. Pp. 103-150. Ed. Snyman H. A., Landbouweekblad and Landbou.com, Media 24. pp. 537.

Snyman, H.A. 2015. Short-term response of southern African semi-arid rangelands to fire: A review on impact on plants. Arid Land Res. Man. 29, 237-254.

Tainton, N.M. \& Hardy, M.B. 1999. Introduction to the concepts of development of vegetation. In: Veld management in South Africa. Ed. Tainton, N.M. Pietermaritzburg: University of Natal press, South Africa. 
Taylor, G., Swanepoel, F.J.C., Webb, E.C. \& Stroebel, A. 2008. Effect of heifer frame size on their subsequent reproductive performance and pre-weaning performance of their calves, Aust. J. Exp. Agric., 48, 945-949.

Van Rooyen, N. 2002. Veld management in the savannas. In: Game ranch management Ed. Bothma, J. du. P. 4th edition, Pretoria: Van Schaik, South Africa.

Webb, E.C. \& Erasmus, L.J., 2013. The effect of production system and management practices on the quality of meat products from ruminant livestock, S. Afr. J. Anim. Sci., 43(3):413-423.

Whitehead, D.C. 2000. Nutrient elements in grasslands. Soil-Plant-Animal Relationships. Oxon: CABI Publishing. 